\title{
The influence of humidity fluxes on offshore wind speed profiles
}

\author{
R. J. Barthelmie ${ }^{1,2}$, A. M. Sempreviva ${ }^{3,2}$, and S. C. Pryor ${ }^{1,2}$ \\ ${ }^{1}$ Atmospheric Science Program, College of Arts and Sciences, Indiana University, Bloomington, IN 47405, USA \\ ${ }^{2}$ Wind Energy Division, Ris $\varnothing$ DTU National Laboratory for Sustainable Energy, 4000 Roskilde, Denmark \\ ${ }^{3}$ Institute of Atmospheric Sciences and Climate, Institute of Atmospheric Sciences and Climate, CNR, I 88046 Lamezia \\ Terme, Italy
}

Received: 30 June 2009 - Accepted: 15 April 2010 - Published: 3 May 2010

\begin{abstract}
Wind energy developments offshore focus on larger turbines to keep the relative cost of the foundation per MW of installed capacity low. Hence typical wind turbine hub-heights are extending to $100 \mathrm{~m}$ and potentially beyond. However, measurements to these heights are not usually available, requiring extrapolation from lower measurements. With humid conditions and low mechanical turbulence offshore, deviations from the traditional logarithmic wind speed profile become significant and stability corrections are required. This research focuses on quantifying the effect of humidity fluxes on stability corrected wind speed profiles. The effect on wind speed profiles is found to be important in stable conditions where including humidity fluxes forces conditions towards neutral. Our results show that excluding humidity fluxes leads to average predicted wind speeds at $150 \mathrm{~m}$ from $10 \mathrm{~m}$ which are up to $4 \%$ higher than if humidity fluxes are included, and the results are not very sensitive to the method selected to estimate humidity fluxes.
\end{abstract}

Keywords. Meteorology and atmospheric dynamics (Ocean-atmosphere interactions; General or miscellaneous)

\section{Introduction and motivation}

By the end of 2009, total installed wind energy capacity was close to $159 \mathrm{GW}$ (GWEC, 2010). Europe is currently the global leader in offshore wind installations and installed capacity in European waters passed $1.5 \mathrm{GW}$ in 2008 , with a further 430-760 MW planned for installation in 2009, and 1100-1180 MW proposed for installation in 2010 (de Vries, 2009). While installed capacity offshore has not grown as fast as anticipated, the European Wind Energy Association

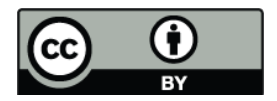

Correspondence to: R. J. Barthelmie (rbarthel@indiana.edu)
(EWEA) estimates that of the total $180 \mathrm{GW}$ wind energy capacity expected to be installed in the European Union (EU) in 2020 between $20 \mathrm{GW}$ and $40 \mathrm{GW}$ will be offshore and that offshore wind farms will comprise half of the total $300 \mathrm{GW}$ wind energy capacity installed in the EU by 2030 . This move towards increased emphasis on harnessing of the offshore wind resource is also manifest at the national level. In 2002, Germany announced a target of 20-25 GW offshore wind energy by 2020-2030. In December 2007, the UK government announced a plan to install $33 \mathrm{GW}$ of offshore wind capacity by 2020 . By 2008, Danish offshore wind farms had a capacity of over $400 \mathrm{MW}$, relative to a total national wind capacity of over $3 \mathrm{GW}$, and an additional $4.6 \mathrm{GW}$ of potential offshore sites had been identified (Danish Energy Authority, 2007).

This move towards increased reliance on offshore deployment of wind turbines provides both new challenges and opportunities (Barthelmie et al., 2009; de Vries, 2008; Musial, 2007). One of the challenges is that turbine deployment offshore coupled with the increase in turbine hub-heights means that wind energy is extending into a historically undersampled region of the atmosphere - the marine boundary layer between $50-200 \mathrm{~m}$ above the surface. The average commercial wind turbine erected in 2007 was close to 1.5 $2.0 \mathrm{MW}$ in installed capacity with a hub-height of 70-90 m and a rotor diameter of 70-90 $\mathrm{m}$ (IEA, 2008). The rotor plane thus extends from about $30 \mathrm{~m}$ to $140 \mathrm{~m}$. The trend is to use even larger turbines in offshore environments and thus extend even higher from the surface (de Vries, 2008).

Wind energy density is proportional to the cube of the wind speed, which leads to unprecedented demands for accuracy in quantifying the entire wind speed probability distribution (and hence the wind resource) which requires better models for wind speed profiles, both on- and off-shore. In situ data at turbine hub-heights and across the turbine blades are rarely available prior to turbine installation offshore, so it remains common practice to vertically extrapolate wind speed measurements from lower measurement heights most

Published by Copernicus Publications on behalf of the European Geosciences Union. 
commonly using simple models of the variation of wind speed with height. However, it is now accepted that there is a need to account for deviations of stability conditions from near-neutral in predicting average vertical profiles of wind speed (Capps and Zender, 2009), and there is increasing evidence that even with inclusion of stability corrections surface layer similarity theory is inadequate for modeling offshore wind speed profiles for wind energy (Gryning et al., 2007; Peña et al., 2008; Tambke et al., 2005).

Here the role of latent heat fluxes in determining the Monin-Obukhov length in marine atmospheres is quantified, together with the importance of this effect on the vertical wind profile. We compare the magnitude of the correction to the logarithmic wind profile implied by inclusion of humidity fluxes to corrections that have been proposed to account for the role of the height of the atmospheric boundary layer in causing deviations from profiles of wind speed derived using standard Monin-Obukhov similarity theory. We conclude by describing the importance of these influences on the vertical wind shear in the context of offshore wind energy.

\section{Wind speed profiles}

\subsection{Monin-Obukhov similarity theory}

Monin-Obukhov similarity theory is based on the assumption of a constant flux layer and hence is only applicable within the surface layer. According to the theory, the stability corrected (diabatic) wind speed profile is defined by (Stull, 1988):

$U_{z}=\frac{u_{*}}{\kappa}\left[\ln \frac{z}{z_{0}}-\Psi_{\mathrm{m}}\left(\frac{z}{L}\right)\right]$

where $U_{z}$ is the wind speed at height $z . u_{*}$ is the friction velocity which is related to generation of waves at the sea surface. $\left(u_{*}^{2}=\frac{\tau}{\rho}\right)$, where $\tau$ is the shear stress and $\rho$ is the air density) and the dimensionless drag coefficient $\left(C_{\mathrm{D}}\right)$ $\left(u_{*}^{2}=C_{\mathrm{D}} U_{10}^{2}\right)$, where $U_{10}$ is the wind speed at $10 \mathrm{~m}$ above the surface). $\kappa$ is the von-Karman constant. $z_{0}$ is the roughness length.

$\Psi_{\mathrm{m}}(z / L)$ is the stability function for momentum that describes the deviation from the neutral wind speed profile (Stull, 1988) and depends on the stability index $z / L$ where $z$ is the height above the surface and $L$ is the Monin-Obukhov length.

As shown by Eq. (1), the change of wind speed with height in the surface layer depends not only on the prevailing atmospheric stability but also the surface roughness. The latter varies with wind speed offshore (Charnock, 1955), but due to the very low values for the roughness length even under high wind conditions, variations in $z_{0}$ have a negligible impact on the average vertical profile of wind speeds (Barthelmie, 2001; Frank et al., 2000). Many other physical mechanisms influence wind speed profiles, particularly in the near-coastal zone. These include the effect of the roughness change from land to sea (Sempreviva et al., 1990), swell (Smedman et al., 1999), sea breezes (Simpson, 1994) and low-level jets (Smedman et al., 1996). In this analysis, average rather than instantaneous wind speed profiles are examined and these processes are excluded thus implicitly assuming homogeneous conditions.

Analysis of diabatic wind profiles from the $213 \mathrm{~m}$ meteorological tower at Cabauw in the Netherlands, indicate observed wind speed profiles agree with the similarity functions of the atmospheric surface layer up to at least $100 \mathrm{~m}$ (Holtslag, 1984), but there is increasing evidence that the constant flux layer assumption inherent in Monin-Obukhov similarity theory is invalid at heights above $100 \mathrm{~m}$ over land and possibility lower over sea (Gryning et al., 2007; Tambke et al., 2005). However, using a stability correction to the logarithmic profile (where Eq. 1 is applied with $\Psi_{\mathrm{m}}(z / L)=0$ ) improves predictions relative to observations (Barthelmie, 1999; Motta et al., 2005) and is frequently employed in the absence of proven alternatives. Thus it is assumed here that a stability correction is required and the impact of including humidity fluxes, calculated using different methods, is examined.

\subsection{The Monin-Obukhov stability parameter}

\subsubsection{Theory}

The Monin-Obukhov length $(L)$ is a metric of atmospheric stability and is approximately the height at which buoyancy starts to dominate over mechanically generated turbulence (Stull, 1988):

$L=\frac{-u_{*}^{2}}{\left(\kappa\left(g / \overline{\theta_{\mathrm{v}}}\right)\left(w^{\prime} \theta_{\mathrm{v}}^{\prime}\right)\right)}$

Where the over-bar indicates a time average. $g$ is acceleration due to gravity. $w^{\prime} \theta_{\mathrm{v}}^{\prime}$ is the virtual kinematic heat flux. $\theta_{\mathrm{v}}$ is the virtual potential temperature.

Potential temperature is used to correct temperature to a standard reference pressure (e.g. $1000 \mathrm{mb}$ ) making the assumption that the air parcel is unsaturated and assuming adiabatic (close to near-neutral) conditions:

$\theta=T\left(\frac{1000}{P}\right)^{R / c p}$

where $T$ is temperature. $P$ is the atmospheric pressure. $R$ is the universal gas constant. $c_{p}$ is the specific heat capacity of dry air.

Virtual potential temperature is used to approximate the potential temperature that dry air would have assuming the same pressure and density as a parcel of moist air:

$\theta_{\mathrm{v}}=\theta(1+0.61 q)$

where $q$ is the specific humidity. 
The stability function $\Psi_{\mathrm{m}}(z / L)$ in Eq. (1) in stable conditions is given by (Stull, 1988):

$\Psi_{\mathrm{m}}=-4.7 \frac{z}{L}$

As $L$ is positive, the correction to the wind speed profiles is positive (Eqs. 5 and 1) leading to increased wind shear in stable conditions. For unstable conditions $L$ is negative and the correction is:

$\Psi_{\mathrm{m}}=2 \ln \left(\frac{1+x}{2}\right)-\ln \left(\frac{1+x^{2}}{2}\right)+2 \tan ^{-1}(x)-\frac{\pi}{2}$

Where $x=\left(1-15 \frac{z}{L}\right)^{1 / 4}$

As the absolute value of $L$ increases (or as $z / L \rightarrow 0$ ) conditions tend towards near-neutral, $\Psi_{\mathrm{m}}(z / L) \rightarrow 0$, and the wind speed profile becomes increasingly logarithmic.

The virtual kinematic heat flux (Eq. 2) is related to the combined effect of sensible and latent heat fluxes which may have different boundary conditions offshore because, at the top of the mixed layer, dry air is entrained into the boundary layer and the surface is a source of humidity (i.e. the humidity flux is always upward (Sempreviva and Gryning, 1996)) whereas the air-sea temperature gradient which drives the sensible heat flux at the bottom of the boundary-layer maybe either positive or negative (Yu and Weller, 2007). Over land the role of the latent heat flux is generally much smaller because the surface does not act as an infinite source of water.

As shown in Sempreviva and Gryning (1996), using the dimensionless form of $L(z / L)$, and the definition of virtual potential temperature, Eq. (2) can be rewritten as:

$\frac{z}{L}=-\frac{g \kappa z}{u_{*}^{3} \theta} \overline{w^{\prime} \theta^{\prime}}-0.61 \frac{g \kappa z \theta}{u_{*}^{3} \theta_{\mathrm{v}}} \overline{w^{\prime} q^{\prime}}$

By defining:

$\frac{z}{L_{T}}=-\frac{g \kappa z}{u_{*}^{3} \theta_{\mathrm{v}}} w^{\prime} \theta^{\prime}$

and:

$\frac{z}{L_{q}}=-0.61 \frac{g \kappa z \theta}{u_{*}^{3} \theta_{\mathrm{v}}} w^{\prime} q^{\prime}$

Then:

$\frac{z}{L}=\frac{z}{L_{T}}+\frac{z}{L_{q}}$

where $z / L_{T}$ accounts for sensible heat fluxes and $z / L_{q}$ accounts for humidity fluxes (Sempreviva and Hoejstrup, 1998).

In the marine boundary layer, humidity fluxes are always positive (upwards) at the surface, thus:

- In unstable conditions both sensible heat and latent heat fluxes are positive and $z / L<0$. Since both terms are negative $\frac{z}{L_{T}}+\frac{z}{L_{q}}<\frac{z}{L}$. Adding humidity fluxes therefore results in increased instability.

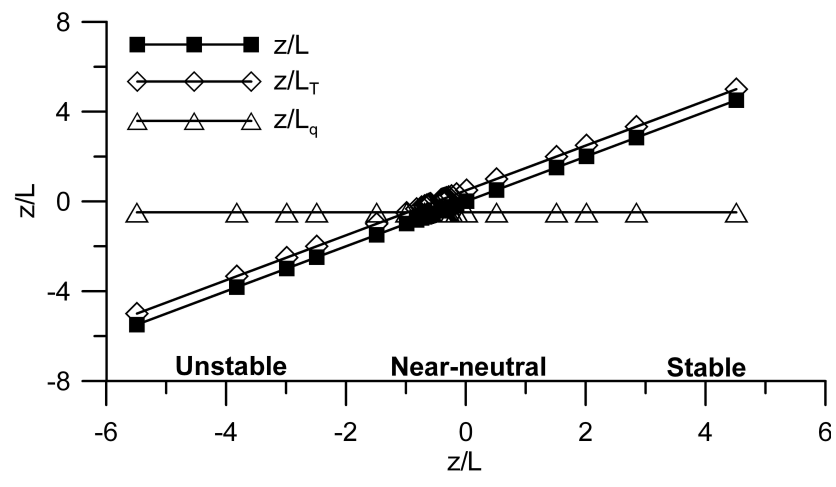

Fig. 1. Contributions of $z / L_{q}$ (latent heat flux contribution) and $z / L_{T}$ (sensible heat flux contribution) to the total value of $z / L$ (Eq. 7) in different stability conditions.

- In stable conditions sensible fluxes are negative and latent heat fluxes are positive. In this case, $\frac{z}{L_{T}}>0, \frac{z}{L_{q}}<0$ thus $\frac{z}{L_{T}}+\frac{z}{L_{q}}<\frac{z}{L}$. Including latent heat fluxes results in decreased stability (i.e. a tendency towards conditions that are closer to neutral).

Figure 1 illustrates the importance of considering $L_{q}$ for a generic case where $z / L_{q}$ is set to -0.2 and $z / L_{T}$ varies between -5 and 5. As indicated above, $z / L$ increases (conditions become more unstable) if $z / L_{q}$ is added in unstable conditions and $z / L$ decreases (conditions become closer to neutral) if $z / L_{q}$ is added in stable conditions.

An issue in wind energy is that while wind speed and temperature profiles (or even sensible heat fluxes derived from a sonic anemometer) may be available to estimate the stability correction, humidity profiles or fluxes are rarely available. If the Monin-Obukhov length is calculated using fluxes derived from a sonic anemometer the derived temperature is the virtual temperature. If, however, the Monin-Obukhov length is calculated by first calculating the Bulk Richardson number (see e.g. Stull, 1988) from temperature differences, these should be corrected to the virtual temperature to account for latent heat fluxes.

Below we assess the magnitude of the stability correction to offshore wind speed profiles based on temperature profiles only (the sensible heat flux) and compare this with values obtained including the latent heat flux in the calculation of the Monin-Obukhov length. There are several methods of estimating the latent heat flux and these are described and compared.

\subsubsection{Parameterizations}

Humidity fluxes are notoriously difficult to measure (Large and Pond, 1982), so bulk formulations are frequently used to estimate the sensible and latent fluxes required to calculate the Monin-Obukhov length (Ruprecht and Simmer, 1991; Subrahamanyam et al., 2009; Wenzel and Kalthoff, 2000; Xu 


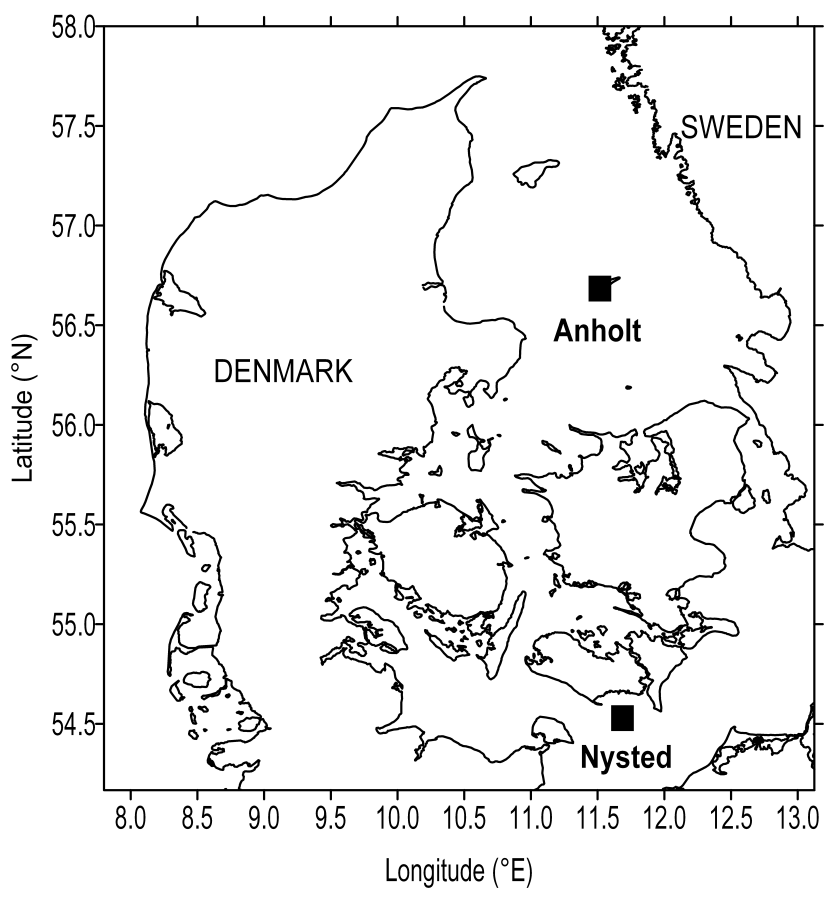

Fig. 2. Location of the sites at Anholt and Nysted in Denmark.

and Qiu, 1997) although errors in the derived humidity fluxes are relatively large in comparison with observations particularly in stable conditions (Rutgersson et al., 2001; Strub and Powell, 1987). One well-known formulation (Beljaars et al., 1989) typically uses the measured temperature profile to determine the sensible heat flux and an iterative solution (Van Ulden and Holtslag, 1985) for the latent heat flux, the potential temperature scale $\left(\theta_{*}\right)$ and the humidity scale $\left(q_{*}\right)$ based on a modified form of the Priestly and Taylor equation (Priestley and Taylor, 1972). This gives $q_{*}$ as:

$q_{*}=\alpha \frac{c_{p}}{\lambda} \frac{s}{(1+\alpha) s+1} \theta_{*}$

Where $c_{p}$ is the specific heat capacity for dry air. $\lambda$ is the latent heat of evaporation. $s$ is the derivative of the water vapor saturation pressure as a function of temperature. $\alpha$ is a constant set to 0.128 .

Once the humidity scale $q_{*}$ has been estimated it is used to calculate the virtual potential temperature:

$\theta_{\mathrm{v} *}=\theta_{*}+0.61 \theta q_{*}$

Which can then be used to determine $L$ from Eq. (2).

These bulk parameterizations were derived principally for use over land and, as can be seen from Eq. (11), the sign of $q_{*}$ is set via the sign of $\theta_{*}$ i.e. if $\theta_{*}$ is positive $q_{*}$ is defined as positive. However the latent heat flux offshore is upward (Sempreviva and Hoejstrup, 1998) i.e. $q_{*}$ is negative. The impact of humidity on the value of the Monin-Obukhov length, $L$, is through the use of $\theta_{\mathrm{v} *}$ rather than $\theta_{*}$ in Eq. (2) and, in stable conditions, $L$ is larger due to the presence of humidity fluxes. Note that the sign of the Monin-Obukhov length (positive or negative) is dictated solely by the temperature flux. From $L$, the stability parameter $(z / L)$ is then determined and the wind speed profile calculated from the wind speed measured at $10 \mathrm{~m}$ (or any other height) using Eq. (1).

\subsection{Role of the boundary layer height}

It has recently been suggested that for wind speeds above 50$80 \mathrm{~m}$ from the surface, deviations from the wind profile based on surface-layer theory and Monin-Obukhov scaling increasingly occur, and at least in stable conditions these deviations are dependent on an additional length scale (the boundary layer height) (Gryning et al., 2007). This has prompted the suggestion that the surface-layer equations for the wind speed profile described in Eq. (1) should be modified in stable conditions as follows (Gryning et al., 2007):

$U_{z}=\frac{u_{*}}{\kappa}\left[\ln \frac{z}{z_{0}}-\Psi_{\mathrm{m}}\left(\frac{z}{L}\right)\left(1-\frac{z}{2 z_{i}}\right)\right]$

Where $z_{i}$ is the boundary-layer height.

In the absence of specific measurements of the boundarylayer height, $z_{i}$ may estimated using (Gryning et al., 2007):

$z_{i}=0.12 \frac{u_{*}}{f_{\mathrm{c}}}$

Where $f_{\mathrm{c}}$ is the Coriolis parameter.

Herein the relative impact of the humidity correction and the boundary layer height correction to wind speed profiles are compared.

\section{Evidence for the importance of latent heat fluxes on the vertical wind profile}

\subsection{Data from the Anholt Experiment}

Data presented here are derived from three intensive measurement campaigns over two week periods on the small Danish island of Anholt (Fig. 2) conducted between September 1990 and October 1992 (Sempreviva and Gryning, 1996). During the experiments, a $22 \mathrm{~m}$ meteorological mast was equipped with standard meteorological equipment in addition to a 3-D sonic anemometer and a fast response hygrometer. The site was situated $10 \mathrm{~m}$ from the coast on the western part of the island giving an offshore fetch of at least $50 \mathrm{~km}$ from $240-360^{\circ}$ and a land fetch from $30-100^{\circ}$.

The resulting data were conditionally sampled by wind direction into 'land' and "sea" fetches and used to compute the partitioning of the stability parameter $z / L$ between the contributions from sensible $\left(z / L_{T}\right)$ and latent heat fluxes $\left(z / L_{q}\right)$ (Fig. 3). While the results exhibit considerable scatter, particularly in wind directions associated with a land fetch due to internal boundary layer growth from the coastline in some directions, data collected from a sea fetch (i.e. under offshore 

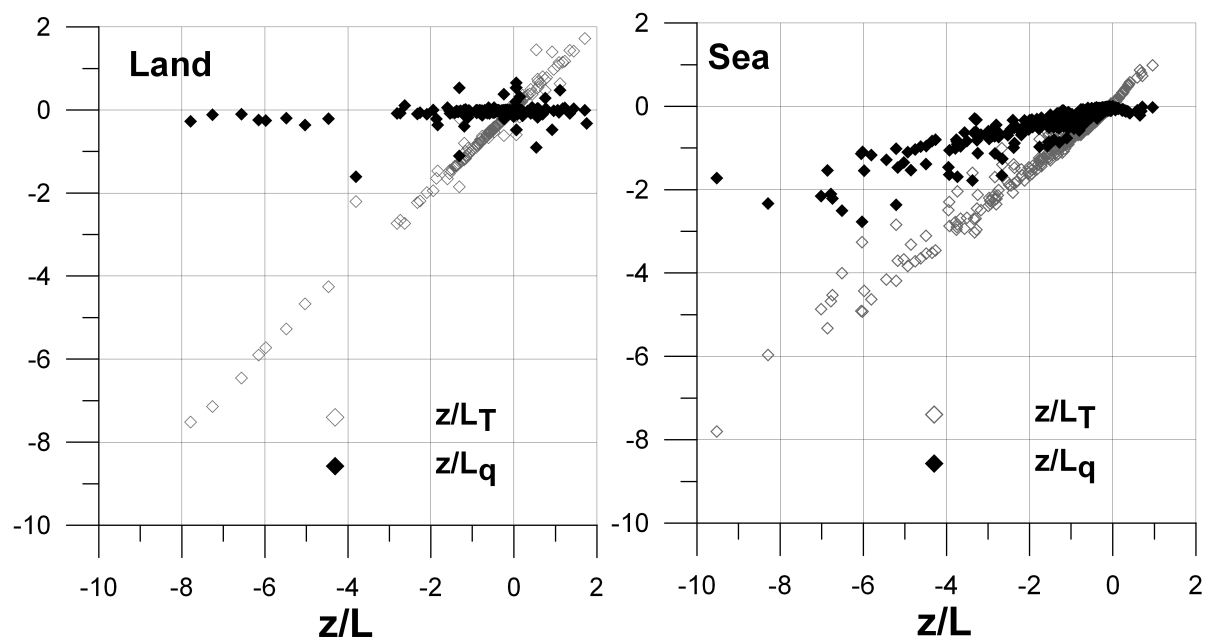

Fig. 3. Partitioning of $z / L$ between $z / L_{T}$ and $z / L_{q}$ for land (left) and offshore (right) conditions using data from Sempreviva and Gryning (1996). Over land the influence of humidity fluxes $\left(z / L_{q}\right)$ is small and $z / L$ is dominated by $z / L_{T}$. The horizontal axis indicates total $z / L$ while the vertical axis shows values for both $z / L_{T}$ and $z / L_{q}$.

conditions) indicate that $z / L_{q}$ can account for up to $30 \%$ of the total $z / L$.

The measurements from Anholt were used to quantify the magnitude of the effect of humidity fluxes on the stability correction to wind speed profiles. In this analysis $L$ is calculated from the sonic anemometer temperature measurements using Eqs. (2-6) and the observed wind speed at $22 \mathrm{~m}$ height extrapolated to $150 \mathrm{~m}$ height using Eq. (1). This is approximately the tip height of current wind turbines being deployed offshore (2-3 MW range). In the first calculations, the Monin-Obukhov length is calculated using only sensible heat flux (i.e. $z / L=z / L_{T}$ ) and in the second set of calculations the latent heat flux is included (i.e. $z / L=z / L_{T}+z / L_{q}$ ) (Fig. 4). In stable conditions, inclusion of humidity fluxes reduces the predicted wind speed at $150 \mathrm{~m}$ height by approximately $5 \%$ relative to a profile computed without their inclusion (Fig. 4). In unstable conditions, latent heat fluxes play a much smaller role in dictating the overall stability and hence there is a negligible effect on wind speed profiles. This is because a change in the value of $L$ in unstable conditions due to humidity increases fluxes forcing conditions to be more unstable and, as shown in Eq. (6), the stability correction to the wind speed profile in unstable conditions tends to be smaller and much less sensitive to the value of $L$ than in stable conditions. Additionally the influence of humidity flux must be small unless the value of the sensible heat flux is small (Mahrt et al., 1998) and this is also consistent with the influence of humidity fluxes being important only in stable conditions.

Assuming that $z / L$ needs to be corrected to include $z / L_{q}$ only in stable conditions, data from Anholt were used to derive an empirical correction to $z / L$ as shown in Fig. 5. Here the ratio $(z / L) /\left(z / L_{T}\right)$ was compared with $z / L_{T}$ for posi-

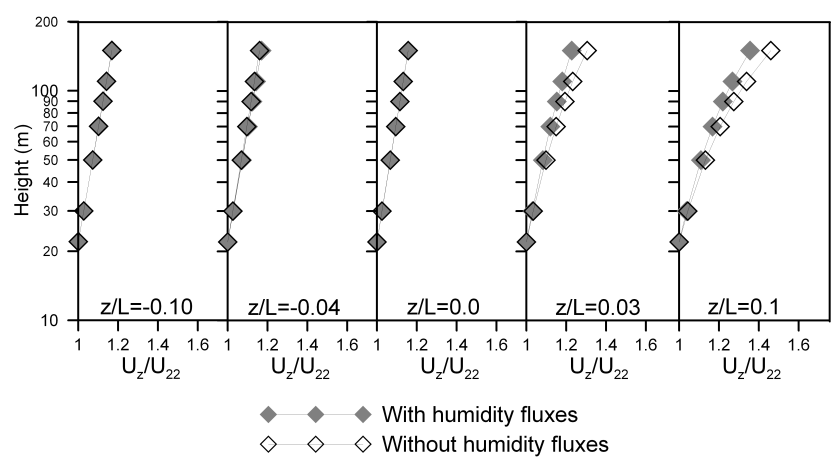

Fig. 4. The influence of humidity fluxes on the wind profiles using data from the Anholt experiment (Sempreviva and Gryning, 1996). The filled symbols are the normalized wind speed profile predicted using Eq. (1) and the experimental $z / L$ including humidity fluxes; the open symbols are the wind speed profile without humidity fluxes. Inclusion of humidity fluxes does not influence the profile for unstable conditions but in stable conditions the profile is driven towards neutral.

tive values of $z / L$ and an empirical relationship derived that can be used to estimate $z / L$ for stable conditions offshore. The corrected wind speed profile calculated from the scaled $z / L_{q}$ is compared with alternative stability corrected wind speed profiles below.

\subsection{Data from the Nysted wind farm}

The generalizability of inferences drawn from the Anholt experiment are evaluated using meteorological data collected from Nysted offshore wind farm (Cleve et al., 2009). The data were analyzed to assess how frequently the conditions 

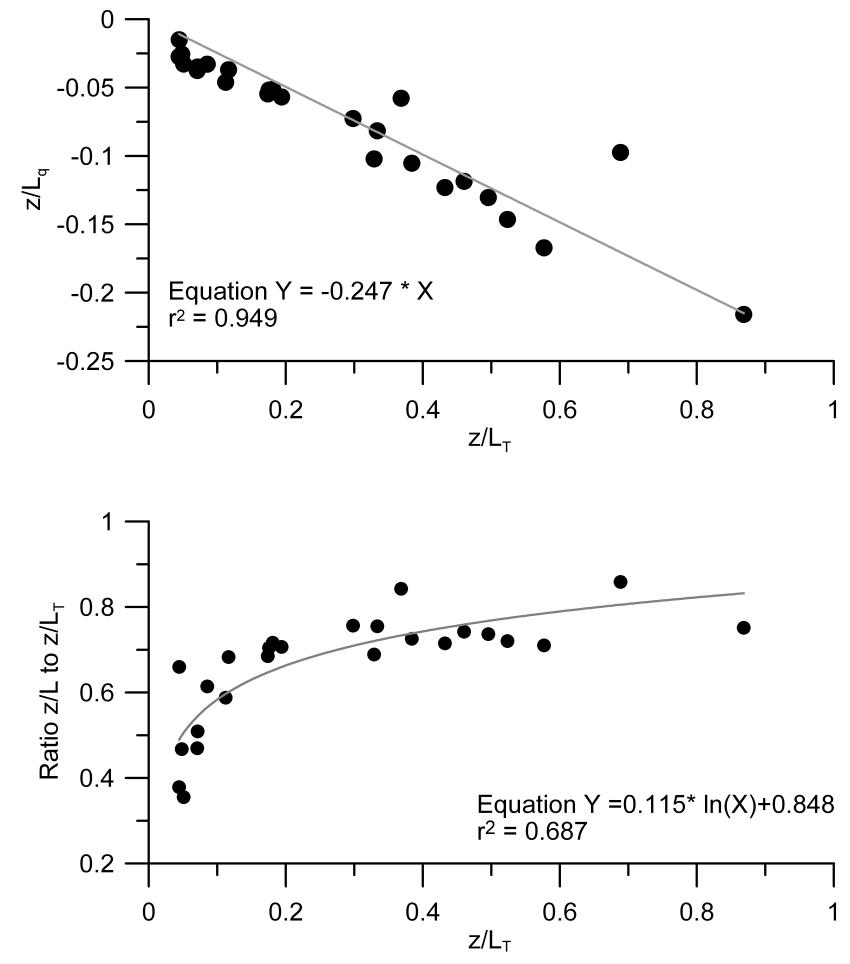

Fig. 5. The relationship between $z / L, z / L_{T}$ and $z / L_{q}$ using data from the Anholt experiment.

likely to be associated with substantial impact of humidity fluxes on the wind speed profile are observed, and to assess the degree to which inclusion of $L_{q}$ in computing $L$ improves the fit between the predicted and observed wind speed profiles. Two years of relative humidity $(\mathrm{RH})$ measurements at $10 \mathrm{~m}$ using a Vaisala HMP45A \& HMP45D temperature and humidity sensor, wind speeds from $10,25,40,55,65$ and $69 \mathrm{~m}$ collected using Ris $\varnothing$ RIS $\varnothing$ P2546 cup anemometers (Pedersen, 2004), and temperature from Ametek pt-100 instruments at 10 and $65 \mathrm{~m}$ were used in the analysis. The RH measurements have an accuracy of $1 \%$, and indicate relatively little seasonal variability, with monthly average RH varying between $79 \%$ and $87 \%$.

Monin-Obukhov length computed from the temperature measurements at 65 and $10 \mathrm{~m}$ and the standard approach of (Beljaars et al., 1989) indicate about $33 \%$ of the observations are in the stable class with $0.05<z / L<1$ (Fig. 6), implying that both the humidity correction and the boundary-layer correction can be important influences on the wind speed profile because both apply under stable conditions. In the following, $L$ was recalculated using different methods to determine $\theta_{\mathrm{v}}$ :

- If no humidity measurements are available, $q_{*}$ can be estimated using procedure from Beljaars et al. (1989) as described in Sect. 2.2.2 except that $q_{*}$ is always negative.

- If RH is available, the specific humidity $q$, where $q$ is

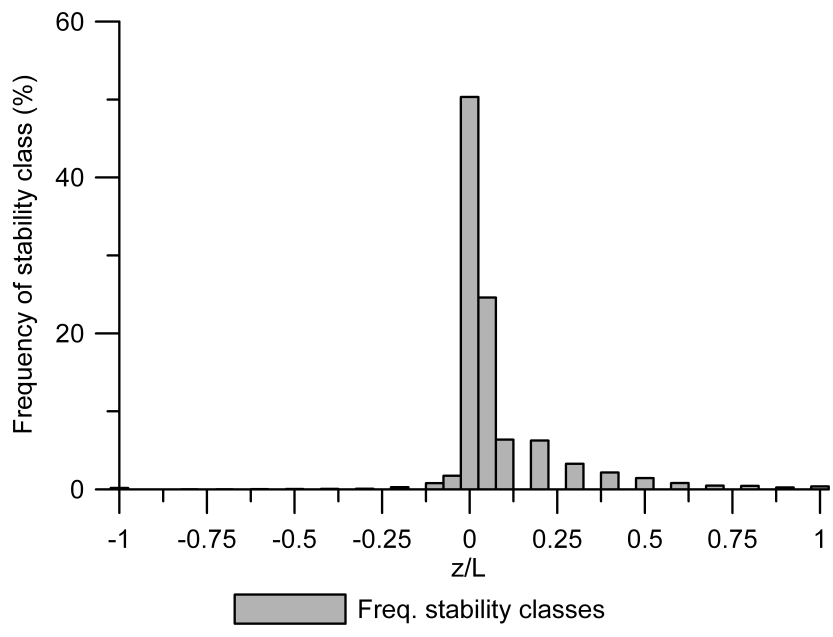

Fig. 6. The frequency of stability class is calculated from meteorological data from the Nysted wind farm over the period June 2004 May 2006. As shown near-neutral conditions $(\operatorname{abs}(z / L)<0.05)$ are the most frequent, but slightly stable to stable $(0.05<z / L<1)$ conditions account for about $33 \%$ of the observations.

the mass of water vapour per unit mass of air, including the water vapour can be calculated from:

$q=\frac{\varepsilon e(1-\varepsilon)}{P}$

Where $\varepsilon$ is the ratio of gas constants for dry air to that of water vapour $(0.622)$.

$e$ is the vapor pressure of water vapor can be derived from the saturation vapor pressure calculated for the measured temperature (see e.g. Stull, 2000) and the relative humidity.

Assuming the surface layer at height $0 \mathrm{~m}$ is saturated with respect to water vapor giving $q_{0}, q_{*}$ can then be calculated as:

$q_{*}=\left(q-q_{0}\right) \kappa /\left(\ln \left(\frac{z}{z_{0 q}}\right)-\Psi_{H}\left(\frac{z}{L}\right)+\Psi_{H}\left(\frac{z_{o q}}{L}\right)\right)$

Where the functions $\Psi_{H}\left(\frac{z}{L}\right)$ and $\Psi_{H}\left(\frac{z_{o q}}{L}\right)$ are assumed to be the same as those for heat and roughness length for humidity, $z_{0 q}$, is defined:

$z_{0 q}=1.3 \times 10^{-4}+0.93 \times 10^{-5} / u_{*}$

Thus six methods were used to determine the wind profile up to $65 \mathrm{~m}$ for each $10-\mathrm{min}$ wind speed measurement at $10-\mathrm{m}$ :

1. Logarithmic: Where Eq. (1) is applied with the stability correction $\Psi_{\mathrm{m}}(z / L)$ set to 0 .

2. Stability: Where Eq. (1) is applied with the stability correction $\Psi_{\mathrm{m}}(z / L)$ applied using the standard parameterization from Beljaars et al. (1989) to compute $L$ except that $q_{*}$ is always negative. 
Table 1. Predicted wind speeds at $69 \mathrm{~m}$ (from an initial height of $10 \mathrm{~m}$ a.m.s.1.) normalized by the observations for 2 years of 10 -min data from the Nysted wind farm. The wind speed predictions are made using 6 approaches:

1. Logarithmic: Where Eq. (1) is applied with the stability correction $\Psi_{\mathrm{m}}(z / L)$ set to 0 .

2. Stability: Where Eq. (1) is applied with the stability correction $\Psi_{\mathrm{m}}(z / L)$ from the standard parameterization of Beljaars et al. (1989) except that $q_{*}$ is always negative.

3. Stability without humidity: Where Eq. (1) is applied with the stability correction $\Psi_{\mathrm{m}}(z / L)$ from the standard parameterization of Beljaars et al. (1989) but setting the latent heat flux to 0 .

4. Stability with measured humidity: Where Eq. (1) is applied with the stability correction $\Psi_{\mathrm{m}}(z / L)$ applied using the parameterization from Beljaars et al. (1989) but with $L_{q}$ derived based on the observed relative humidity at $10 \mathrm{~m}$ as in Eqs. (15-17).

5. Stability with scaled $z / L$ in using the correction for stable cases from Eq. (18).

6. Stability with boundary layer (BL) correction: As 2) but using Eq. (13) for the wind speed profile in stable conditions.

The results are presented as the average in five stability classes defined on the basis of $z / L$, and in terms of a mean of all data periods. Also shown is the Root Mean Square Error (RMSE) for all $65 \mathrm{~m}$ wind speed predictions from $10 \mathrm{~m}$ observations versus the observed wind speed at $65 \mathrm{~m}$.

\begin{tabular}{|c|c|c|c|c|c|c|c|}
\hline & Stable & $\begin{array}{r}\text { Slightly } \\
\text { stable }\end{array}$ & Neutral & $\begin{array}{l}\text { Slightly } \\
\text { unstable }\end{array}$ & Unstable & $\begin{array}{l}\text { Mean of } \\
\text { all data }\end{array}$ & $\begin{array}{l}\text { RMSE } \\
\left(\mathrm{m} \mathrm{s}^{-1}\right)\end{array}$ \\
\hline$z / L$ & $\begin{array}{c}0.05< \\
z / L<1\end{array}$ & $\begin{array}{r}0.01< \\
z / L<0.05\end{array}$ & $|z / L|<0.01$ & $\begin{array}{r}-0.01< \\
z / L<-0.05\end{array}$ & $\begin{array}{r}-1<z / L \\
<-0.05\end{array}$ & & \\
\hline
\end{tabular}

Ratio predicted/observed wind speed at $65 \mathrm{~m}$ height

\begin{tabular}{|c|c|c|c|c|c|c|c|}
\hline 1. Logarithmic & 0.74 & 0.86 & 1.02 & 1.08 & 1.03 & 0.95 & 1.35 \\
\hline 2. Stability & 0.99 & 0.90 & 1.01 & 1.03 & 0.94 & 0.99 & 1.19 \\
\hline 3. Stability without humidity & 1.05 & 0.92 & 1.02 & 1.03 & 0.94 & 1.01 & 1.05 \\
\hline 4. Stability with measured humidity & 1.02 & 0.91 & 1.01 & 1.03 & 0.95 & 1.00 & 0.98 \\
\hline 5. Stability with scaled $z / L$ & 0.94 & 0.90 & 1.01 & 1.03 & 0.94 & 0.95 & 1.09 \\
\hline 6. Stability with boundary-layer correction & 0.88 & 0.90 & 1.01 & 1.03 & 0.94 & 0.97 & 0.95 \\
\hline
\end{tabular}

3. Stability without humidity: Where Eq. (1) is applied with the stability correction $\Psi_{\mathrm{m}}(z / L)$ applied using the standard parameterization from Beljaars et al. (1989) to compute $L$ but setting the latent heat flux to 0 .

4. Stability with measured humidity: Where Eq. (1) is applied with the stability correction $\Psi_{\mathrm{m}}(z / L)$ applied using the parameterization from Beljaars et al. (1989) to compute $L$ but with $L_{q}$ derived based on the observed relative humidity at $10 \mathrm{~m}$ as in Eqs. (15-17).

5. Stability with scaled $z / L$ in using the correction for stable cases given in Fig. 6 where:

$$
\frac{z}{L}=0.115 \ln \left(\frac{z}{L_{T}}\right)+0.848
$$

6. Stability with boundary layer (BL) correction: As 2) but using Eq. (13) for the wind speed profile in stable conditions.

Note that in the first four methods, the value of $z / L$ is changed by the selected parameterization but in methods 5 and 6 only the correction to the profile in stable conditions is changed. The results are shown in Table 1 as the average ratio of predicted to observed wind speeds at $65 \mathrm{~m}$ height for five stability classes. As in previous work (Motta et al., 2005), the use of the stability parameter improves the prediction of the mean wind speed compared to the logarithmic profile. Changes relating to the humidity flux determination (methods 2-4) have a relatively small impact on the mean wind speed profile. Methods 5 and 6 which impact the wind speed profile calculated in stable conditions have a larger impact on the overall wind speed profile because the corrections become relatively large. However, the root mean square error indicates that method 6 (stability with BL correction) gives the smallest error, while the results using measured relative humidity to derive the stability correction are overall slightly better than using the other stability methods. The scaled $z / L_{q}$ method gives a correction which is too large suggesting that the results from Anholt were not generalizable.

The first column in Table 1 shows the ratio of predicted and observed wind speeds at $65 \mathrm{~m}$ for Nysted for the stable class $(1>z / L<0.05)$ where the humidity and boundarylayer corrections have the largest impact. While the differences between the predicted wind speed profiles using 


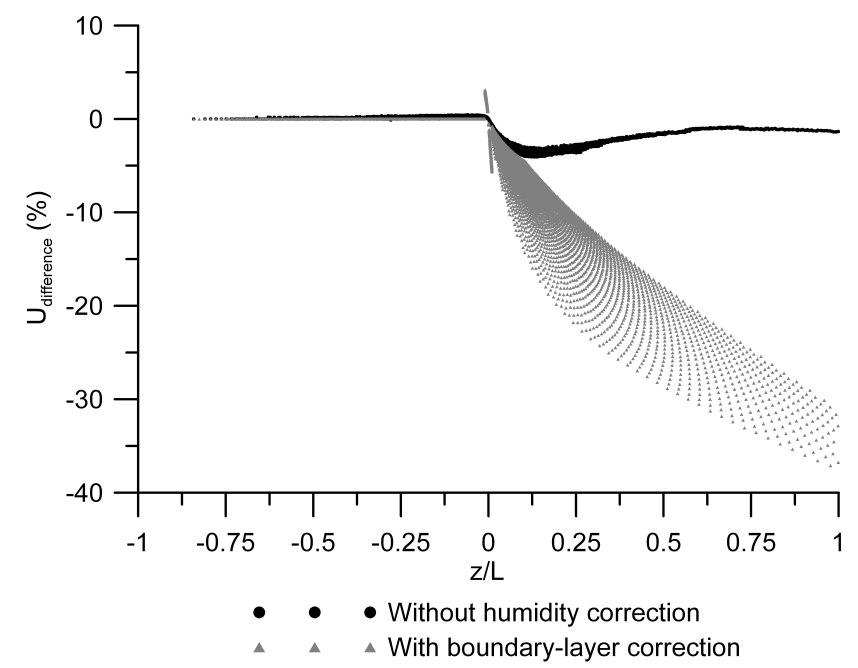

Fig. 7. Difference in predicted wind speeds at $150 \mathrm{~m}$ where $U_{\text {difference }}$ is defined as:

$U_{\text {difference }}=100 \cdot\left(U_{\mathrm{C} 150}-U_{\mathrm{S} 150}\right) / U_{\mathrm{S} 150}$

Where $U_{\mathrm{S} 150}$ is the wind speed at $150 \mathrm{~m}$ extrapolated from $10 \mathrm{~m}$ using $L$ computed using the Beljaars et al. (1989) bulk formulation and Eq. (1). And $U_{\mathrm{C} 150}$ is the wind speed at $150 \mathrm{~m}$ calculated as for $U_{\mathrm{S} 150}$ except (a) without humidity correction where $L$ computed excludes the contribution from $L_{q}$ or (b) with boundary layer correction where the wind speed profile in stable conditions is determined from Eq. (13).

different humidity corrections are relatively small, the inclusion of the role of humidity fluxes does improve the wind speed predictions at $65 \mathrm{~m}$. Excluding the standard latent heat flux correction as specified in Beljaars et al. (1989) gives the highest wind speed prediction at $65 \mathrm{~m}$ as expected. Addition of the boundary layer height correction or the scaled $z / L$ tends to move the profile such that the extrapolated values are more negatively biased relative to the observations at $65 \mathrm{~m}$. However, the overall RMSE is reduced. Although the results are not conclusive the general indications from predicting wind speed profiles at Nysted appear to be; the stability correction to the wind speed profile is needed, the method of calculating the humidity correction is not important, and the scaled $z / L$ and boundary layer correction both over-correct the wind speed profile in very stable conditions. Lack of information regarding these influences adds to the uncertainty in the prediction of the wind speed profile.

\subsection{Comparison of the size of the humidity and boundary-layer corrections}

As mentioned above, wind turbine hub-heights for offshore deployment greatly exceed $65 \mathrm{~m}$. Hence calculations were performed to examine the relative magnitude of the $z / L_{q}$ corrections considered herein on the vertical wind speed extrapolation from $10 \mathrm{~m}$ to $150 \mathrm{~m}$. Wind speeds at $150 \mathrm{~m}$ height were determined using Eqs. (1) and (2) with the standard humidity correction from Beljaars et al. (1989). Two corrections to this profile were then calculated i) computing $L$ i.e. Eq. (2) without humidity fluxes and ii) the correction for the boundary layer height (Eq. 13). Wind speeds at $150 \mathrm{~m}$ were determined for a range of $z / L$ and the difference between the predicted wind speeds compared. As shown in Fig. 7, excluding humidity fluxes makes a difference of up to $4 \%$ in the stable classes. For the boundary-layer correction, there is quite a wide range of wind speed predictions for similar $z / L$ values using Eq. (13) because of the sensitivity of the boundary-layer correction to estimated $z_{i}$. At low wind speeds, $u_{*}$ is low, $z_{i}$ is small and the boundary-layer correction becomes large. For moderately stable conditions (where $z / L<0.1$ ), the magnitude of the boundary-layer correction and the humidity correction are of similar magnitude (a few percent). Such conditions are frequently observed at least at the Nysted wind farm which implies the inclusion of latent heat fluxes in determining $L$ and corrections to the wind profile have a high degree of applicability to the wind energy industry. As conditions become increasingly stable, the magnitude of the boundary-layer correction increases and rapidly becomes very large, while the influence of latent heat fluxes declines.

\section{Conclusions}

As wind energy develops offshore and resource predictions are required for greater heights, better understanding of the wind speed profile over the sea is required. One of the major differences between on- and offshore is the constant presence of strong (upward) latent heat fluxes offshore. In stable conditions, the sensible heat flux is downward and including the influence of latent heat fluxes reduces the stability (drives conditions towards neutral by reducing $z / L$ ) and the vertical wind shear. In unstable conditions, both latent and sensible heat fluxes are upwards and the inclusion of latent heat fluxes reinforces the instability but due to the relatively large sensible heat flux and the moderate correction to the wind speed profile in unstable conditions, the effect on the vertical profile of wind speeds is minor.

Data from measurement campaigns at the island of Anholt in Denmark indicate that the contribution of humidity to fluxes offshore is up to about $30 \%$ in the stability parameter the Monin-Obukhov length. A scaled $z / L$ derived from these data was evaluated against other methods of deriving the humidity contribution using data from an offshore mast at the wind farm site at Nysted in Denmark. Inclusion of the humidity contribution to $L$ has little influence on the average wind speed profile - the mean correction to the wind speed profile is relatively small (less than $2 \%$ at $65 \mathrm{~m}$ ), but it does reduce the RMSE of the vertically extrapolated wind speeds. Inclusion of humidity to calculation of $L$ is highly relevant in stable conditions, but the correction is 
relatively insensitive to the precise mechanism used to compute $q_{*}$. Both the scaled $z / L$ approach for humidity and a recently published correction for the height of the boundary layer over-correct the wind speed profile in very stable conditions and thus under-predict shear at the Nysted wind farm.

Moderately stable conditions are frequently observed at offshore sites in northern Europe. Under these conditions the correction resulting from consideration of latent heat fluxes is of the same magnitude as the correction for boundary-layer height, and is worthy of consideration in vertical extrapolation of wind speeds in marine atmospheres. However it must be acknowledged that latent heat fluxes in the north of Europe are relatively modest (Yu and Weller, 2007) and this is an indication that the latent heat correction to the stability parameter could be larger, and hence more important, in other regions (Geernaert and Larsen, 1993).

Understanding the impact of humidity fluxes on wind speed profiles has relevance not only for accurate assessment of current wind energy resources and for the retrieval of wind speeds from satellite images (West and Yueh, 1996), but may also be of importance in considering how wind speed profiles may change in areas which currently experience sea ice during winter but may become ice free under global climate change (Meier et al., 2004) thus changing the stability climate.

Acknowledgements. This work has been funded in part by the National Science Foundation projects (\#0618364 and \#0828655) and the EU Marie Curie Programme, Training Network activity, ModObs [MRTN-CT-19369] Network and by EU project UpWind \#SES6 019945. We would like to acknowledge DONG Energy and Vattenfall for the use of the Nysted meteorological mast data.

Topical Editor F. D'Andrea thanks two anonymous referees for their help in evaluating this paper.

\section{References}

Barthelmie, R. J.: The effects of atmospheric stability on coastal wind climates, Meteorological Applications, 6, 39-48, 1999.

Barthelmie, R. J.: Evaluating the impact of wind induced roughness change and tidal range on extrapolation of offshore vertical wind speed profiles, Wind Energy, 4, 99-105, 2001.

Barthelmie, R. J., Pryor, S. C., and Frandsen, S. T.: Climatological and meteorological aspects of predicting offshore wind energy, in: Offshore wind energy, edited by: Twidell, J. and Gaudiosi, G., Multi-Science Publishing Co. Ltd, 2009.

Beljaars, A. C. M., Holtslag, A. A. M., and van Westrhenen, R. M.: Description of a software library for the calculation of surface fluxes., KNMI, De Bilt, Netherlands, 1989.

Capps, S. B. and Zender, C. S.: Global ocean wind power sensitivity to surface layer stability, Geophys. Res. Lett., 36, L09801, doi:10.1029/2008GL037063, 2009.

Charnock, H.: Wind stress on a water surface, Q. J. Roy. Meteorol. Soc., 81, 639-640, 1955.

Cleve, J., Grenier, M., Enevoldsen, P., Birkemose, B., and Jensen, L.: Model-based analysis of wake-flow data in the
Nysted offshore wind farm, Wind Energy, 12(2), 125-135, doi:10.1002/we.314, 2009.

Danish Energy Authority: Future Offshore Wind Power Sites -2025. Danish Energy Agency. The Committee for $\mathrm{Fu}-$ ture Offshore Wind Power Sites, April 2007, Copenhagen, http://193.88.185.141/Graphics/Publikationer/Havvindmoeller/ Fremtidens_20havvindm_UKsummery_aug07.pdf, 2007.

de Vries, E.: 40,000 MW by 2020: Building offshore wind in Europe, Renewable Energy World, 11(1), 36-47, 2008.

de Vries, E.: Optimism in Offshore Wind, Renewable Energy World, 12(6), 27-37, 2009.

Frank, H. P., Larsen, S., and Højstrup, J.: Simulated wind power offshore using different parameterizations for the sea surface roughness, Wind Energy, 3, 67-79, 2000.

Geernaert, G. and Larsen, S.: On the role of humidity in estimating marine surface layer stratification and scatterometer cross section., J. Geophys. Res., 98, 927-932, 1993.

Gryning, S. E., Batchvarova, E., Brümmer, B., Jørgensen, H. E., and Larsen, S. E.: On the extension of the wind profile over homogeneous terrain beyond the surface boundary layer, Bound.-Lay. Meteorol., 124, 251-268, 2007.

GWEC: No slow-down for global wind energy, Global Wind Energy Council, http://www.gwec.net/, accessed 20 April 2010.

Holtslag, A. A. M.: Estimates of diabatic wind speed profiles from near-surface weather observations., Bound.-Lay. Meteorol., 29, 225-250, 1984.

IEA: IEA Wind Energy Annual Report 2007, http://www.ieawind. org/AnnualReports_PDF/2007/200720IEA20Wind20AR.pdf, 2008.

Large, W. G. and Pond, S.: Sensible and latent heat flux measurements over the ocean, J. Phys. Ocenaogr., 12, 464-482, 1982.

Mahrt, L., Vickers, D., Edson, J., Sun, J., Hojstrup, J., Hare, J., and Wilczak, J.: Heat flux in the coastal zone, Bound. Lay. Meteorol., 86, 421-446, 1998.

Meier, H. E. M., Doescher, R., and Halkka, A.: Simulated distributions of Baltic sea-ice in warming climate and consequences for the winter habitat of the Baltic ringed seal., Ambio, 33, 249-256, 2004.

Motta, M., Barthelmie, R. J., and Vølund, P.: The influence of non-logarithmic wind speed profiles on potential power output at Danish offshore sites., Wind Energy, 8, 219-236, 2005.

Musial, W.: Offshore wind electricity: A viable energy option for the coastal united states, Mar. Technol. Soc. J., 41, 32-43, 2007.

Pedersen, T. F.: Characterisation and Classification of RIS $\varnothing 2546$ Cup Anemometer. Risoe National Laboratory, Roskilde, http:// www.risoe.dk/rispubl/VEA/veapdf/ris-r-1364_ed2.pdf, 2004.

Peña, A., Gryning, S. E., and Hasager, C. B.: Measurements and modelling of the wind speed profile in the marine atmospheric boundary layer, Bound.-Lay. Meteorol., 129, 479-495, 2008.

Priestley, C. H. B. and Taylor, R. J.: On the assessment of surface heat flux and evaporation using large scale parameters, Mon. Weather Rev., 106, 81-92, 1972.

Ruprecht, E. and Simmer, C.: Fluxes of latent heat over the oceans: climatological studies and application of satellite observations, Dyn. Atmos. Oceans, 16, 111-121, 1991.

Rutgersson, A., Smedman, A., and Omstedt, A.: Measured and simulated latent and sensible heat fluxes at two marine sites in the Baltic Sea, Bound.-Lay. Meteorol., 99, 53-84, 2001.

Sempreviva, A. M. and Gryning, S.-E.: Humidity fluctuations in the 
marine boundary layer measured at a coastal site with an infrared humidity sensor, Bound.-Lay. Meteorol., 77, 331-352, 1996.

Sempreviva, A. M. and Hoejstrup, J.: Transport of temperature and humidity variance and covariance in the marine surface layer, Bound.-Lay. Meteorol., 87, 233-253, 1998.

Sempreviva, A. M., Larsen, S. E., Mortensen, N. G., and Troen, I.: Response of neutral boundary layers to changes of roughness, Bound.-Lay. Meteorol., 50, 205-226, 1990.

Simpson, J. E.: Sea breeze and local winds, Cambridge University Press, Cambridge, 1994.

Smedman, A., Hogstrom, U., Bergstrom, H., Rutgersson, A., Kahma, K., and Petterson, H.: A case study of air-sea interaction during swell conditions, J. Geophys. Res., 104, 25833-25851, 1999.

Smedman, A. S., Hogstrom, U., and Bergstrom, H.: Low level jets - a decisive factor for off-shore wind energy siting in the Baltic Sea, Wind Engineering, 20, 137-147, 1996.

Strub, P. T. and Powell, T. M.: The exchange coefficients for latent and sensible heat flux over lakes: dependence upon atmospheric stability, Bound.-Lay. Meterol., 40, 349-361, 1987.

Stull, R. B.: An introduction to boundary layer meteorology, Kluwer Publications Ltd, Dordrecht, 1988.

Stull, R. B.: Meteorology for scientists and engineers, Brooks/Cole, Pacific Grove, CA, 2000.
Subrahamanyam, D. B., Rani, R. I., Ramanchandran, R., Kunhikrishnan, P. K., and Kumar, B. P.: Impact of wind speed and atmospheric stabiity of air-sea interface fluxes over the east Asian Marginal Seas, Atmos. Res., 94(1), 81-90, doi:10.1016/j.atmosres.2008.09.11, 2009.

Tambke, J., Lange, M., Focken, U., Wolff, J., and Bye, J.: Forecasting offshore wind speeds above the North Sea, Wind Energy, 8, 3-16, 2005.

Van Ulden, A. P. and Holtslag, A. A. M.: Estimation of atmospheric boundary layer parameters for diffusion applications., J. Clim. Appl. Meteorol., 24, 1196-1207, 1985.

Wenzel, A. and Kalthoff, N.: Method for calculating the whole-area distribution of sensible and latent heat fluxes based on climatological observations, Theor. Appl. Climatol., 66, 139-160, 2000.

West, R. D. and Yueh, S. H.: Atmospheric effects on the wind retrieval performance of satelliteradiometers. Geoscience and Remote Sensing Symposium, Remote Sensing for a Sustainable Future, 27-31 May 1996.

Xu, Q. and Qiu, C.-J.: A Variational Method for Computing Surface Heat Fluxes from ARM Surface Energy and Radiation Balance Systems, J. Appl. Meteorol., 36, 3-11, 1997.

Yu, L. and Weller, R.: Objectively Analyzed Air-Sea Heat Fluxes for the Global Ice-Free Oceans (1981-2005), B. Am. Meteorol. Soc., 88, 527-539, 2007. 